\title{
SHORT NOTE
}

\section{BOTANICAL ENVELOPES}

\author{
Sadie Barberl \& Steve Scott ${ }^{2}$
}

In the botanical world there has always been a need for seed packets. Around the world and over the years, plant collectors have employed a huge number of both conventional designs and unusual alternatives for storing seed and spores. These include regular letter envelopes, coin envelopes, Ziploc ${ }^{\circledR}$ bags, cloth 'bird bags'(designed to hold birds while they are being ringed) for fleshy seeds, $35 \mathrm{~mm}$ film canisters, glassine envelopes (traditionally used by philatelists), and Tupperware ${ }^{\mathrm{TM}}$ containers. All have proved useful in one way or another for collecting and transporting seed, especially during expeditions into the field, but each also has its drawbacks.

The examples above, while all having their benefits, are not always adequate because, for instance, the seeds can stick to the glue on the packet, such as with glassine envelopes, or they are not always available in the sizes required to contain some seed or fronds. Finally, the packets do not always seal properly which causes a risk of cross contamination or complete loss. Although some of the methods listed above are still used at the Royal Botanic Garden Edinburgh (RBGE), especially glassine packets which have been cut down from $35 \mathrm{~mm}$ negative film strips (without the glue), we have always found that making our own is the most effective and reliable way of collecting and storing seed for short-term use.

Horticultural and research staff at RBGE have used these envelopes for as long as anyone can remember but it has always surprised us to find how little they are used or even known about in the wider horticultural community. When teaching seed collecting techniques to students of horticulture and botany in, for instance, Indonesia and Yemen, starting the classes with this simple method of collecting seed has enthralled the classes and made for much hilarity. The students' first attempt at making a botanical envelope is often a disaster, resulting in envelopes of many shapes and sizes. However, they soon get the hang of it and have ultimately gone on to use them on a daily basis. The beauty of this method is that a wide variety of material, from newspaper to crisp A4 photocopy paper, is suitable. The former is the easiest and cheapest to source as there is virtually always some old newspaper available. However, if one is looking for the 'formula one' material, then we have found that greaseproof paper is the best all-round product, especially for collection in the field. It is clean and lightweight and it allows the seed to

${ }^{1}$ Sadie Barber is a Horticulturist in the Research Collection at the Royal Botanic Garden Edinburgh. Address: 20A Inverleith Row, Edinburgh EH3 5LR

Email: s.barber@rbge.org.uk

${ }^{2}$ Steve Scott is a Senior Horticulturist in the Research Collection at the Royal Botanic Garden Edinburgh.

20A Inverleith Row, Edinburgh EH3 5LR

Email: s.scott@rbge.org.uk 
dry naturally and at an even rate. Also, the packet does not disintegrate when very damp or wet, and it can be made into any size or length which is useful for collecting spores or very long seed pods. A well made envelope can be relied upon to hold the smallest of seed, or spores, without leaking. Finally, once finished with, the envelope can be placed in the paper recycle bin.

The origin of the botanical envelope probably lies with the Japanese art of Origami practiced in Japan since the early 17th century (Wikipedia, 2009). 'Oru' means folding and 'kami' means paper. There are a number of origami designs that produce self-sealing products, and the design we use at RBGE for botanical envelopes is a particularly versatile one.

We have only touched upon the origins and use of the botanical envelope; its simplicity speaks for itself. In writing this we would like to take this method of making them to a wider audience in the hope it will be used by many more people and that others will come to the same conclusion that the students in Indonesia and Yemen did - 'Why haven't we used this before?'

The following diagrams, and pictures taken in the field (Figs. 2 to 7 ), show how easy they are to make. So good luck and have fun!

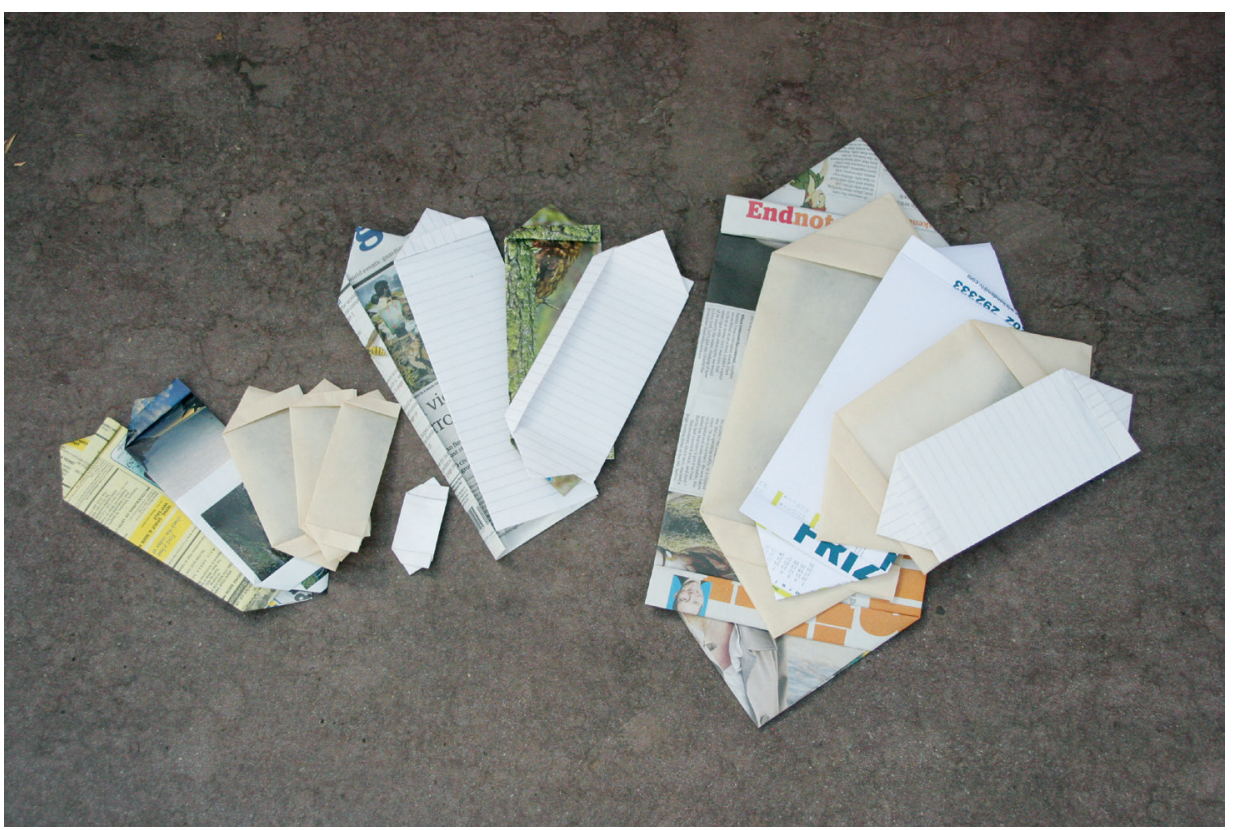

Fig. 1 Collection of botanical envelopes. Photo: Sadie Barber. 

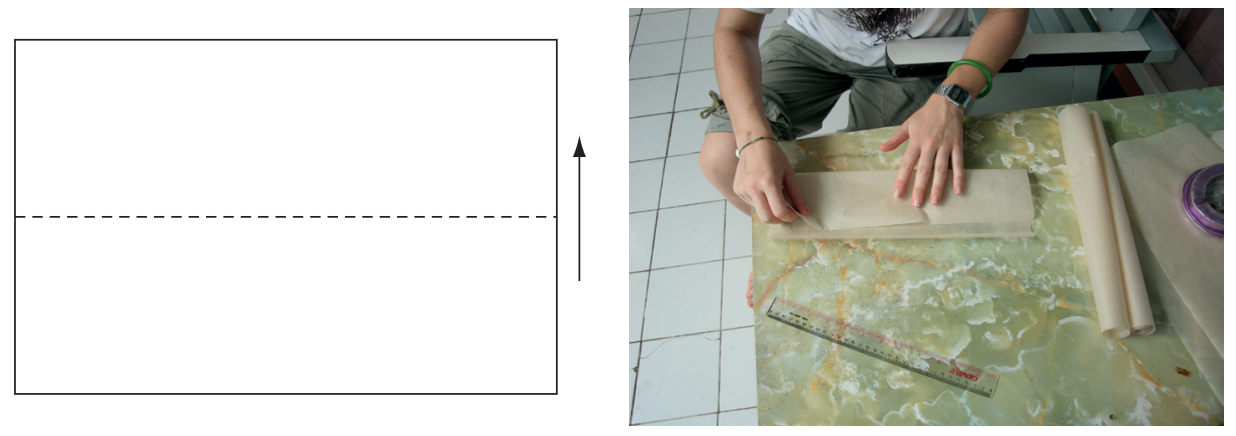

Fig. 2 Fold the paper in half lengthways. Photo: Sadie Barber.
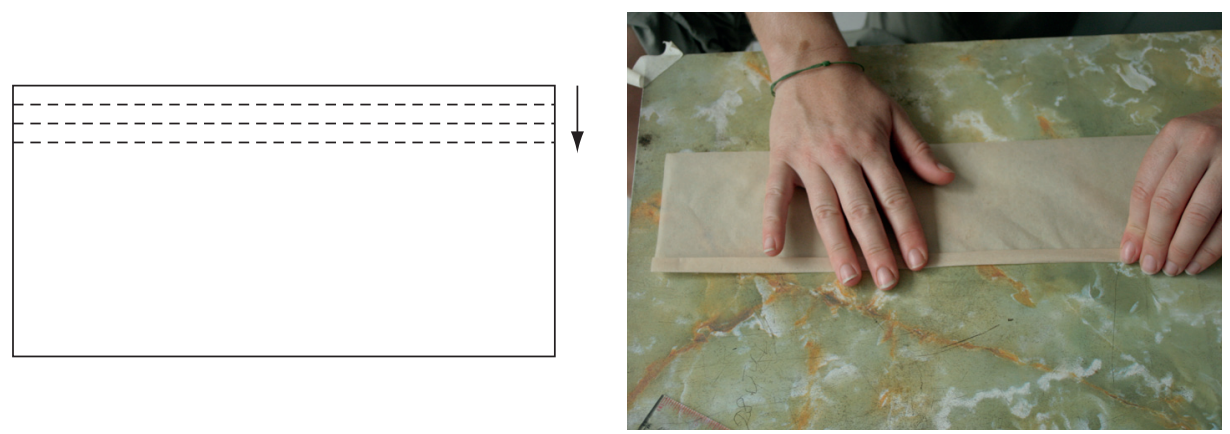

Fig. 3 Fold over the two edges twice to make a flat tube. Photo: Sadie Barber.
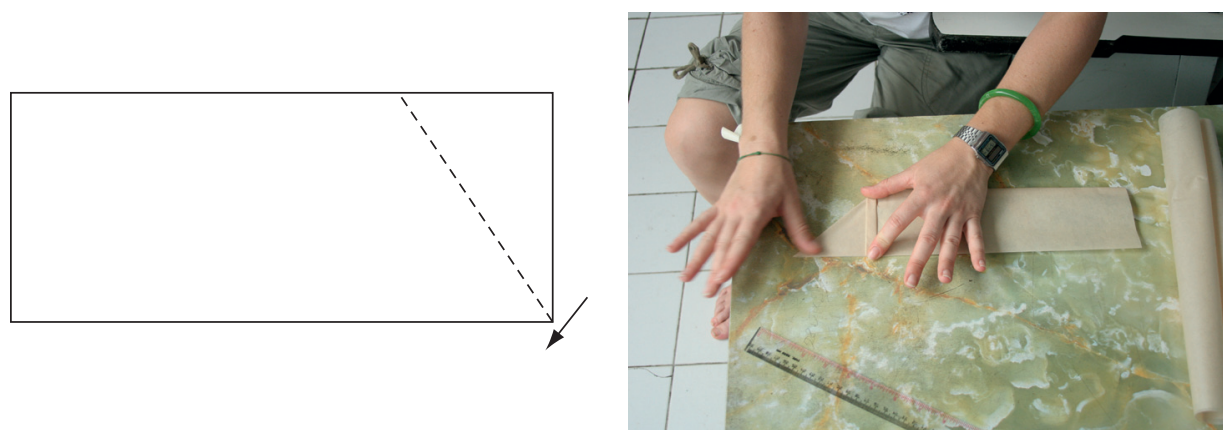

Fig. 4 Place page with sealed edge face down. Fold the top corner back to form a triangle. Photo: Sadie Barber. 

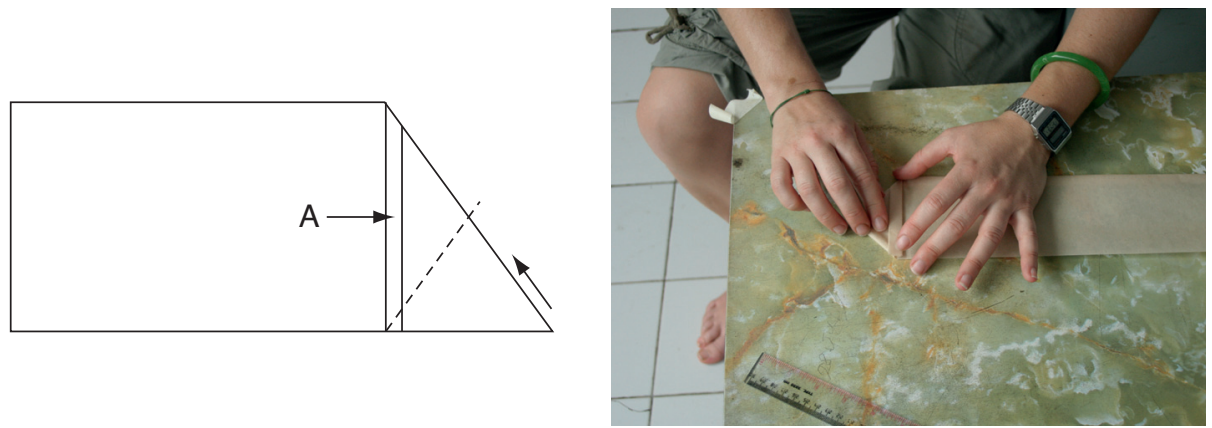

Fig. 5 Fold the other corner back in the same way, tucking the point in under the flap (A). Photo: Sadie Barber.
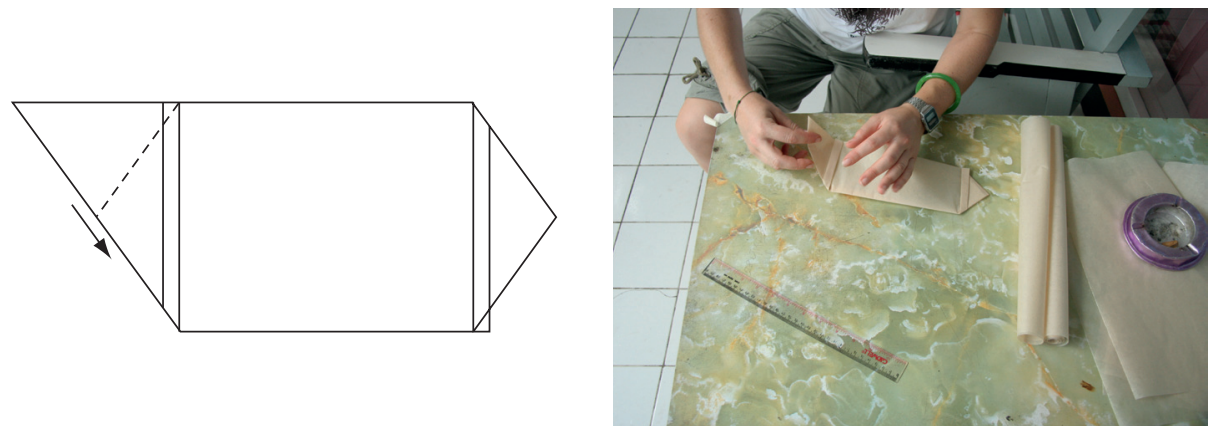

Fig. 6 Repeat the triangle folds at the other end. Photo: Sadie Barber.
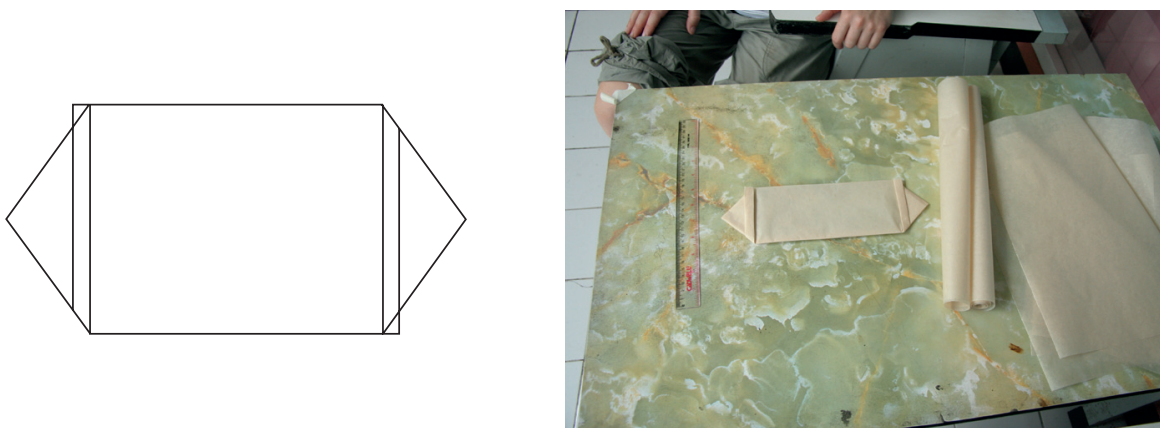

Fig. 7 The finished envelope. Photo: Sadie Barber.

\section{REFERENCE}

WIKIPEDIA. Available at: www.wikipedia.com (Accessed: May 2009) 